\title{
Aplicação e análise da pressão turística como indicador ambiental no Parque Estadual do Jalapão (TO)
}

\author{
Application and analysis of tourist pressure as an \\ environmental indicator in Jalapão State Park (TO, Brazil)
}

\author{
Veruska Chemet Dutra, Afonso Rodrigues Aquino
}

RESUMO: O presente artigo visa analisar a aplicabilidade ou não do monitoramento do turismo com o foco na sustentabilidade por meio de indicadores chave do Turismo sustentável propostos pela Organização Mundial do Turismo. A aplicação foi feita em um estudo de caso na unidade de conservação Parque Estadual do Jalapão - PEJ, localizado no Estado do Tocantins, Brasil. Esta é uma pesquisa de caráter interdisciplinar, que teve como norteador o método dedutivo cujo resultado, o indicador Pressão do PEJ, será apresentado. Conclui-se que os pontos chave do turismo sustentável analisados com foco em indicadores ambientais são uma importante ferramenta de avaliação e quantificação desta atividade no destino em estudo e se mostrou adequada para o monitoramento da região. Foi igualmente possível traduzir os principais impactos ambientais que ocorrem nos atrativos e sua intensidade, o que viabilizou uma análise que objetiva traçar caminhos para a correção e prevenção dos impactos apresentados.

PALAVRAS-CHAVE: Indicadores; Turismo; Sustentabilidade; Jalapão.

\section{ABSTRACT}

This study aims to analyze whether the monitoring of tourism focused on sustainability is applicable or not through the key indicators of sustainable tourism proposed by the World Tourism Organization. The application of the indicators was made in a case study in Jalapão State Park (JSP) conservation unit, in Tocantins state, Brazil. This is an interdisciplinary research guided by a deductive method, which result, the indicator of pressure of JSP, will be presented. It was concluded that the key points of the sustainable tourism, when analyzed focused on environmental indicators, are an important tool for evaluating and quantifying the activity at the destination studied, being suitable for monitoring for the region. It was also possible to translate the main environmental impacts affecting the attraction and its intensity, facilitating analysis devoted to creating ways to prevent and correct the current impacts.

KEYWORDS: Indicators; Tourism; Sustainability; Jalapão. 


\section{Introdução}

A partir dos anos 70 surge um novo olhar em todos os setores sociais e econômicos, tendo como proposta uma nova "leitura" sobre as realidades sociais e dos problemas que envolvem a produção e o consumo de bens e serviços afim de pensar em um desenvolvimento sustentável.

O documento elaborado em 1987 Nosso Futuro Comum coloca esse novo desenvolvimento como um processo de mudança em que a exploração dos recursos, a orientação dos investimentos, os rumos do desenvolvimento tecnológico e a mudança institucional estão de acordo com as necessidades atuais e futuras (CMMAD, 1991).

A proposta de um desenvolvimento sustentável passa a ser discutida em todas as atividades econômicas em desenvolvimento e a partir da década de 80 começa a ser discutida na atividade do turismo que se consolida mundialmente, apresentando resultados de crescimento econômico e de desenvolvimento social e contraditoriamente, aliado a esse fator de desenvolvimento, surgiram os primeiros resultados negativos dessa atividade.

Os impactos socioculturais e as consequências no meio natural começaram a se evidenciar, implicando em uma nova ótica de discussão sobre essa atividade, denominada de turismo sustentável que deveria estar ligada não somente à economia, mas também ao meio ambiente e ao contexto social (SWARBROOKE, 2000).

Assim estudos sobre o desenvolvimento sustentável da atividade turística começam a buscar um modelo de planejamento adequado para as destinações turísticas, sendo em 1997, apresentado pela Organização Mundial do Turismo (OMT, 1997) os indicadores chave do turismo sustentável como uma proposta de gestão da atividade. Os indicadores propostos são: Proteção do Atrativo (PA), Impacto Sociocultural (IS), Processo de Planejamento (PP), Satisfação do Turista (ST), Satisfação da Comunidade (SC), Contribuição do Turismo na Economia Local (CTEL), Intensidade de Uso (IU), Pressão (P), Ecossistemas Críticos (EC), Gestão de Resíduos Sólidos (GRS) e o indicador Satisfação do Trade Turístico (STT).

Diante da abordagem dos indicadores do turismo sustentável propostos pela OMT, os resultados que serão apresentados fazem parte de um projeto de pesquisa que visa analisar a aplicabilidade ou não do monitoramento do turismo com o foco na sustentabilidade, por meio desses indicadores, com aplicação em um estudo de caso na unidade de conservação Parque Estadual do Jalapão-PEJ, localizado no Estado do Tocantins. Nesse artigo são apresentados os resultados do indicador ambiental Pressão.

\section{Indicadores chave do turismo sustentável}

O desenvolvimento sustentável proposto no documento Nosso Futuro Comum, passou a ser a partir da década de 70 o foco das discussões e reflexões de uma sociedade em desenvolvimento, impondo à mesma uma 
nova maneira de se pensar o desenvolvimento aliado não somente a fatores econômicos, mas também sociais e de qualidade ambiental.

Como estratégia desse novo pensar surgiram ferramentas com objetivo de se "medir" os efeitos do desenvolvimento sobre o meio ambiente, pensando na utilização dos recursos não somente no presente, mas também no futuro por outras gerações, era a vertente da sustentabilidade. Assim surgem os indicadores com a proposta de cumprir esses objetivos (FURTADO, 2009).

Os indicadores forneceriam subsídios à formulação de políticas nacionais e acordos internacionais, bem como a tomada de decisão por atores públicos e privados. A proposta também tinha a finalidade de dar maior concretude e funcionalidade ao conceito de sustentabilidade, através da descrição da interação entre a atividade antrópica e meio ambiente (OMT, 1997).

Nesse contexto, o planejamento de um desenvolvimento aliado a tão falada sustentabilidade passa ser constantemente discutido e colocado como um dos grandes desafios do momento para a sociedade. Consequentemente, essa nova vertente de pensamento passa a influenciar outros setores, analogamente considerados de grande importância econômica, social e ambiental, como as atividades relacionadas ao turismo e meio ambiente.

Diante desse contexto a OMT, apresenta a proposta de um turismo sustentável sendo aquele ecologicamente suportável em longo prazo, economicamente viável, assim como ética e socialmente equitativo para comunidades locais (OMT 1997).

Para auxiliar na gestão e monitoramento desse novo turismo em 1997 a OMT lança os indicadores chave do turismo sustentável, descritos no Quadro 1:

Quadro 1: Indicadores Chave do Turismo Sustentável - OMT.

Table 1: Key Indicators of Sustainable Tourism - UNWTO.

\begin{tabular}{|c|c|}
\hline Indicador & Descrição \\
\hline Proteção do Atrativo (PA) & Classifica o nível de proteção do atrativo turístico; \\
\hline Intensidade de Uso (IU) & $\begin{array}{l}\text { Identifica a intensidade de uso do atrativo turístico, através da } \\
\text { sua capacidade de carga }\end{array}$ \\
\hline Impacto Social (IS) & Indica os efeitos do turista na comunidade \\
\hline $\begin{array}{l}\text { Controle do Desenvolvimento } \\
\text { da Atividade Turística (CDAT) }\end{array}$ & Determina o nível de planejamento turístico do destino \\
\hline Gestão de Dejetos (GD) & $\begin{array}{l}\text { Indica a existência ou não de tratamento e controle adequados } \\
\text { de resíduos sólidos no município receptor do fluxo de turistas }\end{array}$ \\
\hline Satisfação do Turista (ST) & $\begin{array}{l}\text { Demonstra o nível de satisfação dos turistas, com a oferta } \\
\text { técnica (alojamentos, restaurantes, entretenimentos, transito } \\
\text { local, receptividade e o atrativo) }\end{array}$ \\
\hline $\begin{array}{l}\text { Satisfação da Comunidade } \\
\text { (SC), }\end{array}$ & $\begin{array}{l}\text { Indica o nível de satisfação da comunidade local com a } \\
\text { atividade turística; }\end{array}$ \\
\hline $\begin{array}{l}\text { Contribuição do Turismo na } \\
\text { Economia local (CTEL) }\end{array}$ & $\begin{array}{l}\text { Indica o nível de contribuição do turismo na economia local em } \\
\text { épocas de temporada }\end{array}$ \\
\hline Pressão $(\mathrm{P})$ & Indica os níveis de pressão dos turistas sobre o local \\
\hline Ecossistemas Críticos (EC); & $\begin{array}{l}\text { Indica o nível de vulnerabilidade de espécies da fauna e da } \\
\text { flora local. }\end{array}$ \\
\hline
\end{tabular}

Fonte: Autoria própria dos autores elaborada com base em OMT (1997).

Source: Authors' own authorship based on UNWTO (1997) 
Os indicadores de sustentabilidade do turismo, são vistos, como sinalizadores do progresso da atividade e sua relação com a comunidade, recursos ambientais, economia e o turista (OMT, 1997).

Segundo a organização, por meio dos indicadores da sustentabilidade turística, os gestores turísticos estarão em melhores condições de identificar questões emergenciais, o que permitirá a sua prevenção e mitigação; identificar impactos, o que facilitará o desenvolvimento de ações antes que ocorram os problemas; apoiar o desenvolvimento do turismo sustentável, identificar limites e oportunidades; fomentar a responsabilidade dos gestores, promover adoção de decisões responsáveis embasadas em conhecimentos.

Os indicadores apresentados não possuem uma metodologia de mensuração e avaliação, cada destinação turística escolhe as ferramentas que considera confiáveis de seleção de itens que irão compor os indicadores e suas respectivas metodologias de mensuração e avaliação deles de acordo com a OMT (2005).

A OMT recomenda que os itens selecionados para comporem 0 indicador-chave propostos recebam pontuações e que os indicadores sejam classificados e tenham notas mínima zero e máxima 10 para uma maior compreensão dos resultados.

A preocupação em se mensurar os efeitos do turismo em áreas protegidas tem feito com que os países se organizem para criar mecanismos de monitoramento que garantam a conservação dessas áreas.

Em se tratando de estudos realizados no Brasil, pode-se destacar o realizado pelo Ministério do Turismo em 2007 (Estudos da Competitividade do Turismo Brasileiro e as Propostas de Indicadores de Sustentabilidade), tendo como objetivo discutir a atividade do turismo nacional e apresentar indicadores que podem ser aplicados no país, mas não apresenta metodologias para aplicação destes, o que demonstra a necessidade de aprofundamento sobre aplicação e análises de indicadores em destinos turísticos no Brasil.

\section{Procedimentos metodológicos}

Foi utilizada a metodologia proposta por NEATUS/UFT (2008) para o Parque Estadual do Jalapão, como forma de se monitorar os impactos ambientais nos atrativos, com uma adaptação da sua mensuração final para análises dos resultados, de acordo com a proposta do estudo. A composição do Indicador foi dividida em dois grupos: Impactos 1 e Impactos 2.

Impactos 1 (Peso 1): Foram considerados os impactos ambientais que podem ser fixos, não aparecem em um primeiro momento e podem ou não ser recuperados com ações a médio e longo prazo.
1.Raízes expostas;
2.Árvores com gravuras;
3.Erosões;
4.Solo descoberto pela vegetação em área próxima ao atrativo principal;

Revista Brasileira de Ecoturismo, São Paulo, v.11, n.3, ago-out 2018, pp. 311-334. 
5.Ausência da vegetação em torno do atrativo principal;

6. Qualidade da água do atrativo para banho.

Impactos 2 (Peso 2): Foram considerados os impactos ambientais que geralmente são causados pelo turista ou gestores do atrativo e podem ser recuperados com ações a curto prazo.

1.Índices de fogo;

2.Árvores derrubadas;

3.Árvores quebradas;

4. Lixo em locais inadequados;

5.Sinais de vandalismo;

6.Cheiro de lixo;

7.Cheiro de urina;

8.Fossa aberta;

9.Presença de entulhos;

10.Rastros de pisoteio em área proibida nas Dunas.

Para os atrativos Dunas e Trilha da Serra do Espírito Santo, não foi incluído o monitoramento da qualidade da água para banho, pois são atrativos que não dispõem desse recurso, e o impacto rastros de pisoteio foi considerado apenas no atrativo Dunas.

A metodologia consistiu em um questionário com a descrição de todos os impactos citados e os pesquisadores analisavam a quantidade (pequena, regular ou grande) que foi encontrada nos atrativos ao final de todos os períodos de monitoramento do turismo no Parque. A Tabela 1 descreve detalhadamente o protocolo criado para a mensuração do indicador.

Tabela 1: Protocolo de mensuração Impactos 1.

Table 1: Measurement Protocol Impacts 1.

\begin{tabular}{|c|c|c|}
\hline \multicolumn{3}{|c|}{ Impactos 1} \\
\hline Descrição & \multicolumn{2}{|c|}{ Critérios de pontuação numa escala de 0 a 10.} \\
\hline $\begin{array}{c}\text { Itens observados do } \\
\text { questionário }\end{array}$ & Pontuação das Respostas & Cálculos \\
\hline $\begin{array}{l}\text { a) Raízes expostas } \\
\text { b) Árvores com gravuras } \\
\text { c) Erosões } \\
\text { d) Solo descoberto pela } \\
\text { vegetação em área } \\
\text { próxima ao atrativo } \\
\text { principal } \\
\text { e) Ausência da Vegetação } \\
\text { em torno do atrativo } \\
\text { principal }\end{array}$ & $\begin{array}{l}\text { "Pontuação máxima de } 10 \\
\text { pontos } \\
\text { 1.Não }=10 \text { pontos } \\
\text { 2.Sim em pequena } \\
\text { quantidade }=7,5 \text { pontos } \\
\text { 3.Sim em regular quantidade } \\
=5 \text { pontos } \\
\text { 4.Sim em grande quantidade } \\
=0 \text { ponto }\end{array}$ & $\begin{array}{l}\text { Cálculo 1: Média de cada } \\
\text { item observado por } \\
\text { temporada em cada } \\
\text { atrativo } \\
\text { Somatório dos pontos de } \\
\text { cada dia do item } \\
\text { observado } N^{\circ} \text { de itens } \\
\text { observados } \\
\text { Cálculo 2: Média de cada } \\
\text { temporada } \\
\text { Somatório das médias de } \\
\text { cada item observado na } \\
\text { temporada por atrativo / } \\
\mathrm{N}^{\circ} \text { de atrativos } \\
\text { monitorados }\end{array}$ \\
\hline
\end{tabular}


Para análise da qualidade da água para banho, o cálculo foi realizado somente para os atrativos Fervedouro das Bananeiras e Cachoeira do Formiga.

Foram realizadas as amostragens das águas dos atrativos turísticos em 04 pontos demarcados ao longo da extensão dos corpos aquáticos, considerado a jusante e montante e os critérios utilizados para a escolha dos pontos amostrais foram: presença de atividades humanas e animais próximas às margens do Riacho.

O período de coleta de amostragem foi feito entre os meses de fevereiro e novembro de 2015. Todas as amostras foram coletadas no período da manhã no horário das 8 às $11 \mathrm{~h}$. A coleta foi feita com frascos de vidro autolavável, não tóxico, de boca larga e tampa à prova de vazamento.

As amostras coletadas foram transportadas em caixas térmicas, em temperatura em torno de $10^{\circ} \mathrm{C}$, sendo que o tempo para a realização das análises não excedeu 24 horas, conforme recomendações descritas em Standard Methods for the Examination of Water and Wastewater - 20aㅡ edição (APHA/AWWA/WEF, 1992). Na contagem dos microrganismos foi utilizada o Método Colilert - sistema patenteado por IDEXX Laboratories (utilizado para detecções simultâneas, identificações específicas e confirmativas de coliformes totais e $E$. coli em água continental natural ou tratada).

A análise final foi realizada de acordo com Art. 20 da Resolução CONAMA 274/2000, BRASIL, 1986. Informa que as águas doces, salobras e salinas destinadas à balneabilidade (recreação de contato primário) terão sua condição avaliada nas categorias própria e imprópria. Segundo o mesmo documento, as águas consideradas próprias poderão ser subdivididas nas seguintes categorias:

a) Excelente: quando em $80 \%$ ou mais de um conjunto de amostras obtidas em cada uma das cinco semanas anteriores, colhidas no mesmo local, houver, no máximo, 250 coliformes fecais (termotolerantes) ou 200 Escherichia coli ou 25 enterococos por 100 mililitros;

b) Muito Boa: quando em $80 \%$ ou mais de um conjunto de amostras obtidas em cada uma das cinco semanas anteriores, colhidas no mesmo local, houver, no máximo, 500 coliformes fecais (termotolerantes) ou 400 Escherichia coli ou 50 enterococos por 100 mililitros;

c) Satisfatória: quando em $80 \%$ ou mais de um conjunto de amostras obtidas em cada uma das cinco semanas anteriores, colhidas no mesmo local, houver, no máximo 1.000 coliformes fecais (termotolerantes) ou 800 Escherichia coli ou 100 enterococos por 100 mililitros.

As análises das amostras foram realizadas no laboratório de Físicoquímica do Instituto Federal de Educação do Tocantins, Campus Palmas, sob a supervisão de um professor pesquisador da área de controle ambiental, com formação em Química. 
As análises finais das amostras que consistiram em atrativo próprio para banho ou impróprio foram pontuadas da seguinte forma para adequação ao estudo proposto:

-Próprio para banho $=10$ pontos

-Impróprio para banho $=0$ pontos.

Para a média final dos Impactos 1 foi considerado:

Somatório total das médias de cada temporada / $\mathrm{N}^{\circ}$ de temporadas monitoradas e quanto aos impactos do grupo 2, a Tabela 2 descreve os critérios que foram adotados.

Tabela 2: Protocolo de mensuração Impactos 2.

Table 1: Measurement Protocol Impacts 2.

\begin{tabular}{|c|c|c|}
\hline \multicolumn{3}{|c|}{ Impactos 2} \\
\hline Descrição & \multicolumn{2}{|c|}{ Critérios de pontuação uma escala de 0 a 10 . } \\
\hline $\begin{array}{l}\text { Itens observados do } \\
\text { questionário }\end{array}$ & Pontuação das Respostas & Cálculos \\
\hline $\begin{array}{l}\text { a) Índices de fogo na mata } \\
\text { b) Árvores derrubadas } \\
\text { c) Árvores quebradas } \\
\text { d) Lixo em locais inadequados } \\
\text { e) Sinais de vandalismo } \\
\text { f) Cheiro de lixo } \\
\text { g) Cheiro de urina } \\
\text { h) Fossa aberta } \\
\text { i) Presença de entulhos } \\
\text { j) Rastros de Pisoteio em área } \\
\text { proibida nas Dunas }\end{array}$ & $\begin{array}{l}\text { *Pontuação máxima de } 10 \\
\text { pontos } \\
\text { Não = } 10 \text { pontos } \\
\text { Sim em pequena quantidade } \\
=7,5 \text { pontos } \\
\text { Sim em regular quantidade }= \\
5 \text { pontos } \\
\text { Sim em grande quantidade = } \\
0 \text { ponto }\end{array}$ & $\begin{array}{l}\text { Cálculo 1: Média de } \\
\text { cada item observado } \\
\text { por temporada em cada } \\
\text { atrativo } \\
\text { Somatório dos pontos } \\
\text { de cada dia do item } \\
\text { observado } N^{\circ} \text { de itens } \\
\text { observados } \\
\text { Cálculo 2: Média de } \\
\text { cada temporada } \\
\text { Somatório das médias } \\
\text { de cada item observado } \\
\text { na temporada por } \\
\text { atrativo / } \mathrm{N}^{\circ} \text { de atrativos } \\
\text { monitorados }\end{array}$ \\
\hline & $\begin{array}{r}\text { Média Total Impactos } 2= \\
\text { (Nota máxima de } 10 \text { pontos) }\end{array}$ & $\begin{array}{l}\text { Cálculo 3: Somatório } \\
\text { total das médias de } \\
\text { cada temporada } / \mathrm{N}^{\circ} \text { de } \\
\text { temporadas } \\
\text { monitoradas }\end{array}$ \\
\hline
\end{tabular}

Indicador Pressão FINAL:

Somatório das Médias Finais do Indicador Pressão de cada atrativo

4 (quatro atrativos) 
O resultado foi analisado de acordo com a avaliação proposta pela OMT que considera indicador com notas:

0 a 4,9 = Avaliação Insatisfatória;

5 a 7,9 = Avaliação Satisfatória;

8 a 10 = Avaliação Excelente.

\section{A região do Jalapão}

O Jalapão é uma região brasileira (vide Figura 1) formada pelos Estados da Bahia, Piauí, Maranhão e Tocantins, com território total de 53,3 mil $\mathrm{Km}^{2}$, dessa área $34.113 \mathrm{mil} \mathrm{km}^{2}$ estão dentro do Estado do Tocantins. $\mathrm{O}$ território tocantinense é formado por 8 municípios, sendo os mais importantes, pela sua localização próxima a atrativos turísticos o município de São Felix do Tocantins, Mateiros, e Ponte Alta do Tocantins (SEPLAN, 2003).

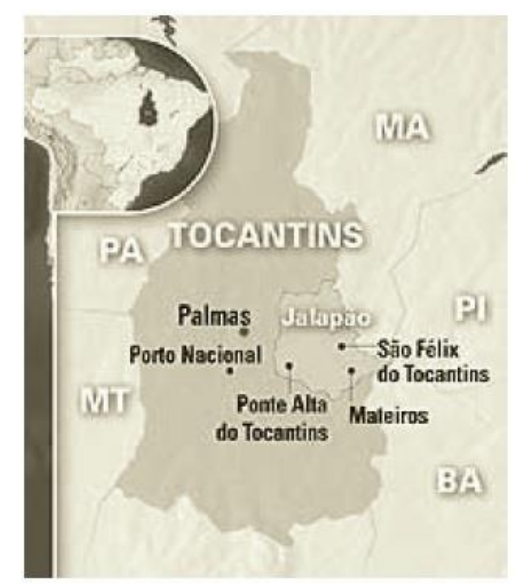

Figura 1: Mapa de Localização Jalapão.

Figure 1: Location Map Jalapão.

Fonte: www.bsb.netium.com.br/ivan/ialapao/jalapao.jpg

Source: www.bsb.netium.com.br/ivan/jalapao/jalapao.jpg

Por meio da lei federal $n^{0} 9.985$ de 18 de julho de 2000, foi criada a unidade de conservação Parque Estadual do Jalapão com aproximadamente 150.000 hectares. As características dessa região são representadas por um bioma de cerrado, caatinga e Amazônia, o que torna o seu ecossistema muito frágil e com espécies ameaçadas de extinção como onças e lontras (BEHR, 2004).

O lugar possui atrativos turísticos naturais que propiciam a prática do ecoturismo, e vem sendo explorado turisticamente de maneira desordenada, pois os esforços voltados para o planejamento turístico, mostram-se ineficazes.

Os atrativos turísticos que são focos desse estudo no PEJ são as Dunas (veja Figura 2), Trilha da Serra do Espírito Santo (veja Figura. 3), Fervedouro das Bananeiras (veja Figura. 5) e Cachoeira do Formiga (veja 
Figura. 6) que compreendem os atrativos que são considerados os mais visitados devido às suas singulares.

\section{Dunas}

As Dunas (vide Figura. 2) são um recurso natural, que hipoteticamente foram formadas pela intensa erosão das escarpas da serra do Espírito Santo, que se encontram logo à frente da formação. Há evidências dessa estreita relação, pois a coloração de ambas e sua proximidade espacial (em torno de $200 \mathrm{~m}$ entre o alto da escarpa e o início das dunas) são sugestivas para se estabelecer essa correlação entre a escarpa, como fornecedora de sedimentos, e as dunas, como áreas de acúmulo desses sedimentos.

Outro aspecto para corroborar com essa hipótese é a presença de imensa alcova na escarpa, formada pela retirada de sedimentos arenosos. Há uma diferença significativa de altitude entre o alto da escarpa $(700 \mathrm{~m})$ e 0 início das dunas $(500 \mathrm{~m})$, que serviriam como depósitos de material arenoso provindo da escarpa (SEPLAN, 2003).

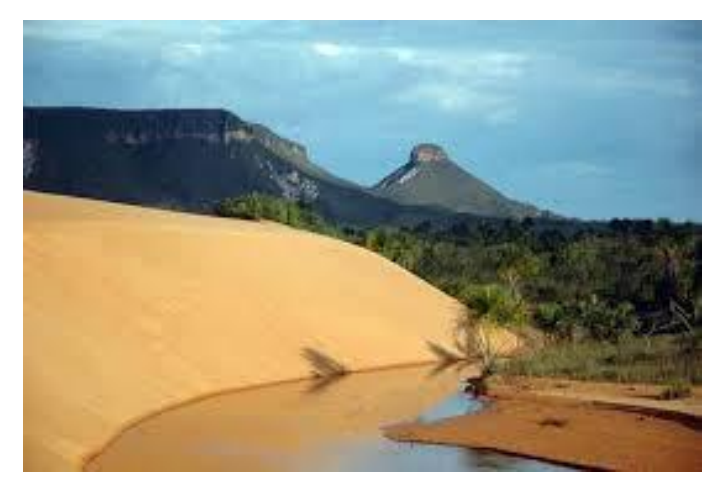

Figura 2: Dunas.

Figure 2: Dunes.

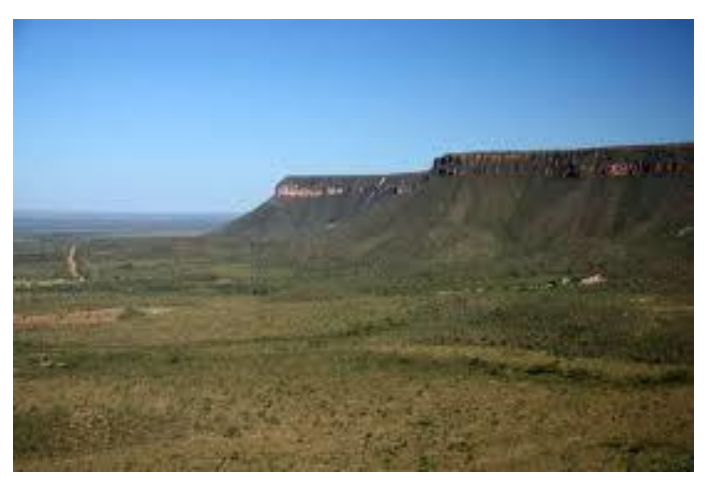

Figura 3: Serra do Espírito Santo Figure 3: Serra do Espírito Santo

Fotos: Dutra (2016)

Photos: Dutra (2016)

\section{Serra do Espírito Santo}

A Serra do Espírito Santo (vide Figura 3) está situada na região sudoeste do PEJ, com uma dimensão aproximada de $22 \mathrm{~km}$ de comprimento e $9 \mathrm{~km}$ de largura na sua parte mais larga. (SEPLAN, 2003).

Como a serra faz parte do cenário que compõe o atrativo Dunas, foi criada uma trilha que possui uma extensão aproximada de $3600 \mathrm{~m}$ e, ao final, um mirante (onde se encontram as escarpas erosivas (vide Figura 4) que dá a visão da formação das Dunas. 


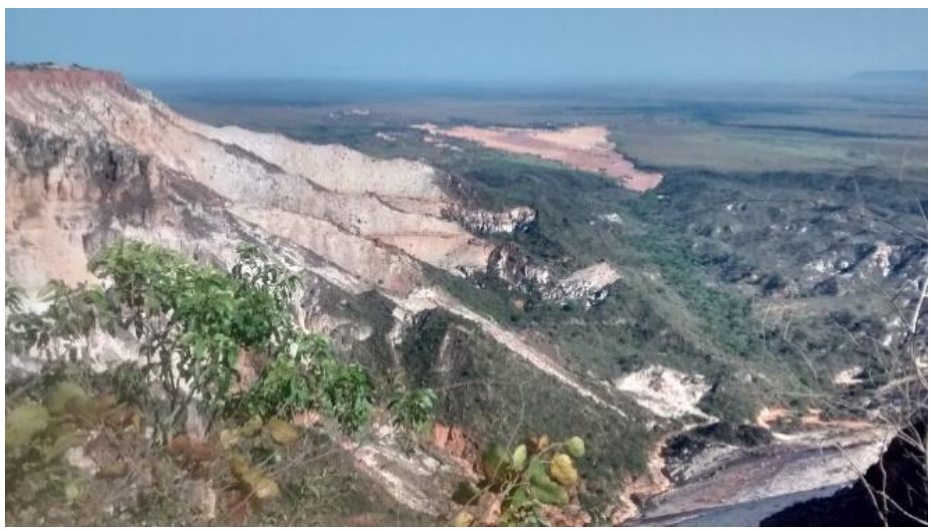

Figura 4. Escarpas erosivas, mirante da Serra do Espírito Santo. Figure 4: Erosive escarpments, view point of Serra do Espírito Santo.

Foto: Dutra (2016). Photo: Dutra (2016)

\section{Fervedouro}

O Fervedouro é o nome dado ao local da ressurgência hídrica que brota do solo, que forma uma espécie de piscina natural, cuja submersão não é possível. Esse fenômeno se torna possível se o lençol freático surge repentinamente, ou se houver um canal direto com reservatórios subterrâneos (NEATUS/UFT, 2008).

$\mathrm{Na}$ região do Jalapão, o aparecimento desse fenômeno é muito comum, sendo registrados mais 30 fervedouros no circuito turístico que vai de Ponte Alta do Tocantins a São Félix do Tocantins. Dos fervedouros, o mais procurado é o das Bananeiras (vide Figura. 5), localizado próximo ao município de Mateiros. Foi o primeiro atrativo com essas características explorado na região, tendo aparecido em mídia nacional e internacional, despertando o interesse de curiosos que passaram a explorar a região para conhecê-lo, em busca de aventura. Isso ocorreu há aproximadamente 20 anos.

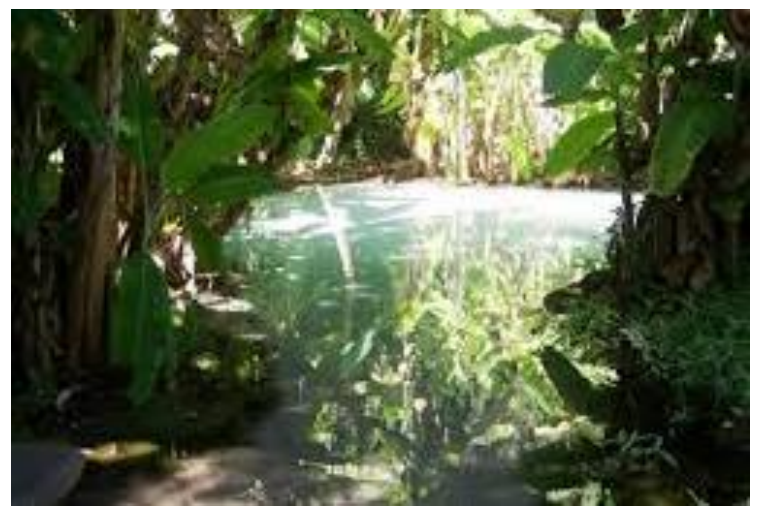

Figura 5: Fervedouro das Bananeiras.

Figure 5: Bananeiras Fervedouro.

Fotos: Dutra (2016). Photos: Dutra (2016). 


\section{Cachoeira do Formiga}

A Cachoeira do Formiga (vide Figura 6), também um dos principais atrativos da região, é uma queda d'água formada por uma nascente a poucos metros. Possui uma cor verde esmeralda, devido às características de um solo de areias calcárias e rochas, que fica ainda mais expressiva com a incidência dos raios solares. Ao seu redor, vegetação compõe um cenário com árvores altas, samambaias e palmeiras nativas.

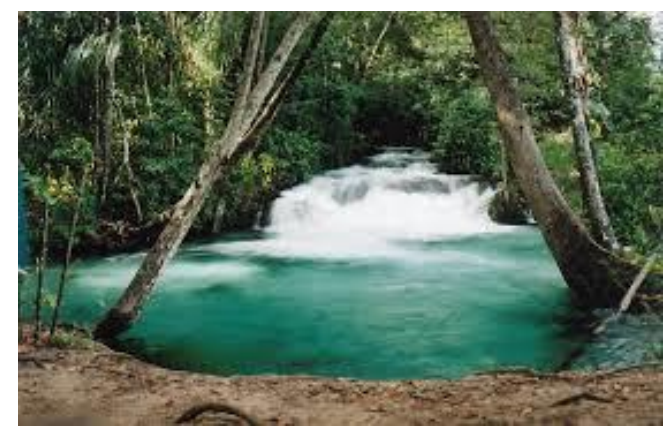

Figura 6: Cachoeira do Formiga. Figure 6: Ant Waterfall.

Fotos: Dutra (2016). Photos: Dutra (2016).

Os atrativos citados compõem o circuito turístico da região do Jalapão, que compreende de Ponte Alta do Tocantins a São Felix do Tocantins.

\section{Indicador Pressão do PEJ}

Os resultados que serão apresentados demonstram um cenário dos atrativos, no que diz respeito ao aparecimento de impactos ambientais, tendo relação direta com o indicador Pressão, pois os impactos monitorados neste estudo são decorrentes da ação do fluxo de turistas nos atrativos e definidos por Correa e Souza (2000, p.84) como

constituído pela gama de modificações ou pela sequência de eventos provocados pelo processo de desenvolvimento turístico nas localidades. As variáveis que provocam os impactos têm natureza, intensidade, direções e magnitudes diferentes, porém os resultados interagem e são geralmente irreversíveis quando ocorrem no meio ambiente natural. Os impactos do turismo são de três ordens: 1- Econômicos, 2 Socioculturais e 3 - Ambientais.

No presente estudo, o indicador Pressão está relacionado com a pressão que esse fluxo tem causado ao ambiente, considerando os impactos como resíduos, raízes expostas, sinais de vandalismos, a qualidade da água do atrativo para banho, ou seja, os impactos ambientais que 
surgem, por exemplo, no desenvolvimento da infraestrutura para o turismo, num incorreto manejo de resíduos gerados pela atividade, nas cicatrizes na paisagem geradas pelo crescimento da infraestrutura nas áreas naturais e pelo volume de visitantes que afeta os ecossistemas mais frágeis (DIAS, 2003, p.78).

O resultado do indicador Pressão teve como nota final 7,6. O indicador mostrou que a pressão que os atrativos vêm sofrendo com o turismo encontra-se em uma escala satisfatória, quando analisada de modo geral. Veja, agora, essa análise por atrativo, esboçada na Figura 7.

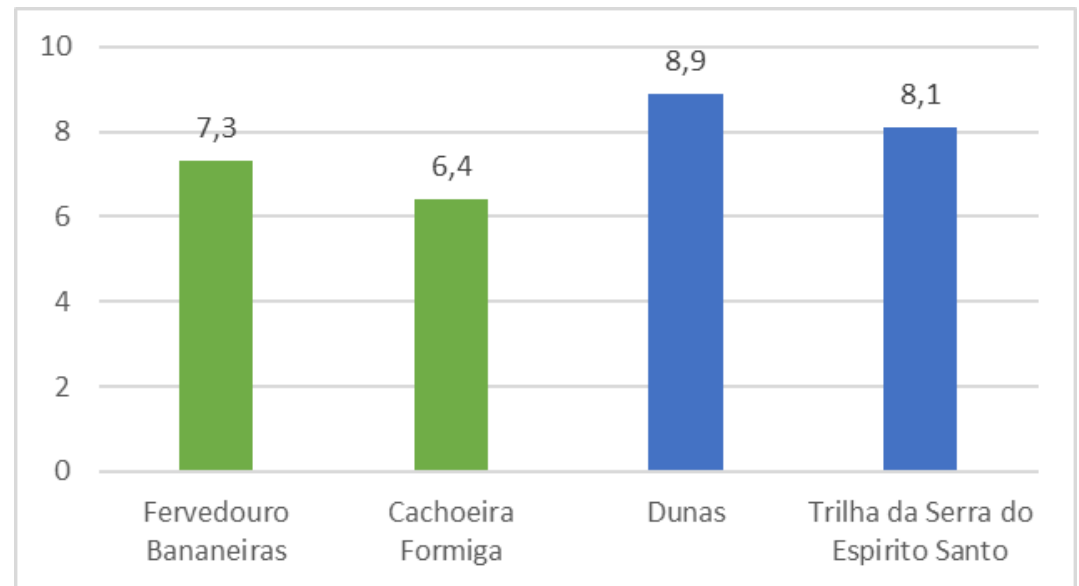

Gráfico 1: Indicador $P$ de cada atrativo.

Graph 1: Indicator P of each attractiveness.

Como pode-se observar no Gráfico 1, quando são analisados os indicadores $P$ de cada atrativo, percebe-se que se formaram dois grupos: 0 grupo dos atrativos que se encontram no nível de pressão em uma escala excelente, que são Dunas e a Trilha da Serra do Espírito Santo, e o grupo que se encontra em uma escala de pressão satisfatória (Fervedouro Bananeiras e Cachoeira do Formiga). A análise dos impactos do atrativo Fervedouro das Bananeiras está demonstrada nos Gráficos 2 e 3.

O Gráfico 2 representa os impactos 1 do atrativo, como pode ser verificado, os impactos mais críticos que são encontrados no local são as raízes expostas e o solo descoberto pela vegetação em área próxima ao atrativo principal, sendo sua ocorrência encontrada e analisada em grande parte dos períodos monitorados (vide Figura 7). 


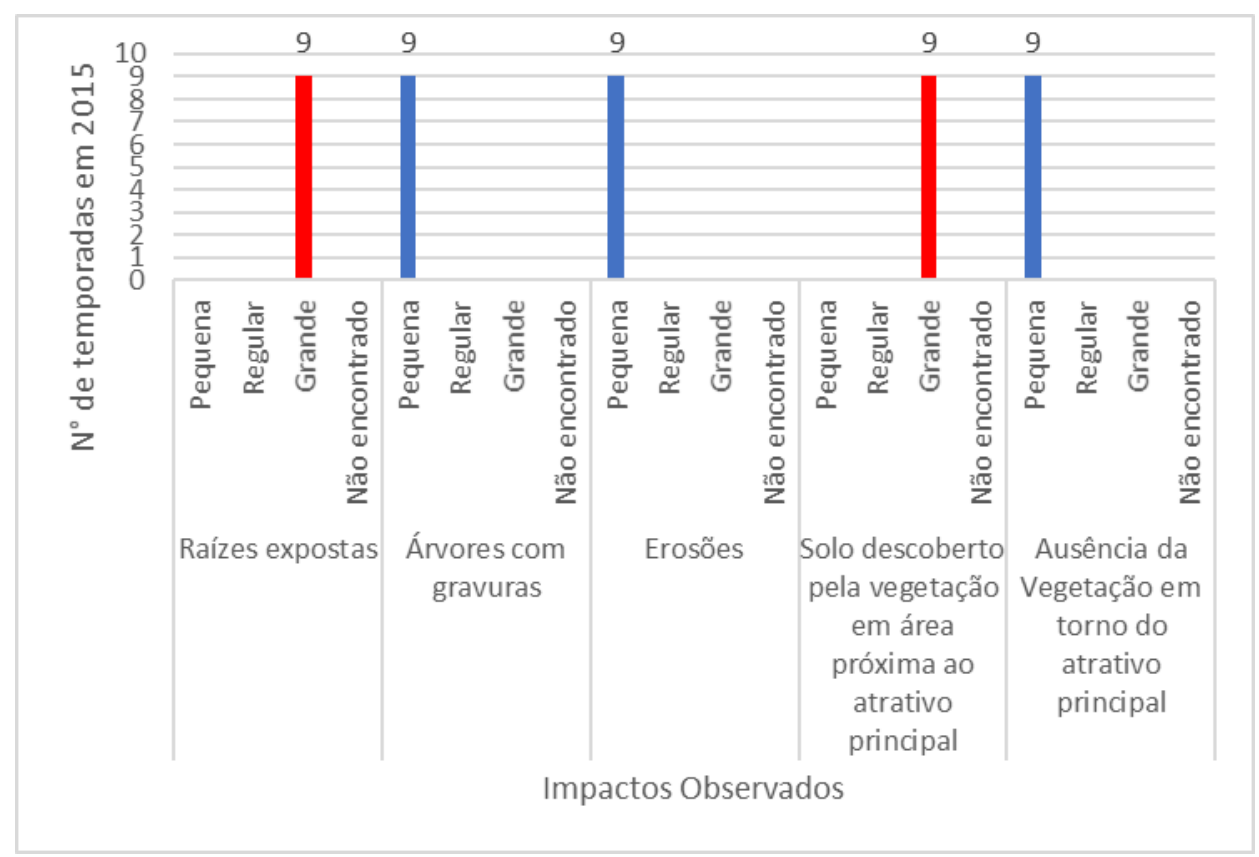

Gráfico 2: Impactos 1 Fervedouro das Bananeiras.

Graph 2: Impacts 1 Fervedouro das Bananeiras.

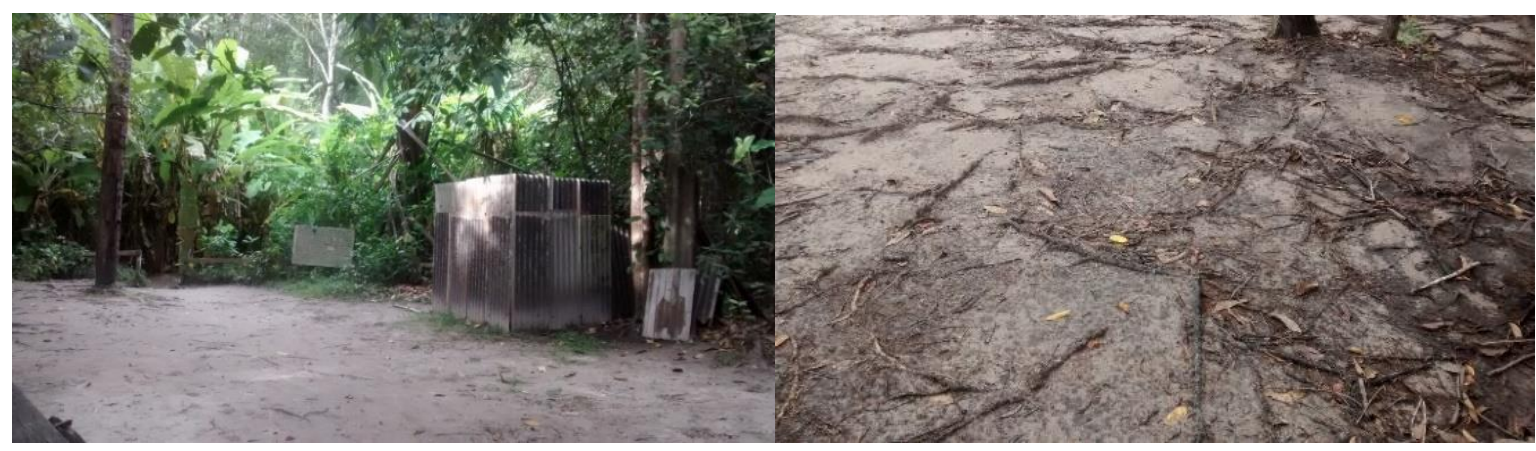

Figura 7: Raízes expostas na área próxima ao atrativo Fervedouro das Bananeiras. Figure 7: Roots exposed in the area near the attractive Fervedouro das Bananeiras.

Fotos: Dutra (2016). Photos: Dutra (2016).

Os demais impactos (árvores com gravuras, erosões, ausência de vegetação em torno do atrativo principal) foram considerados de quantidade pequena e também de ocorrência fixa em todos os períodos do monitoramento.

Os impactos citados (com exceção das gravuras nas árvores) possuem seu aparecimento além de uma relação com o turista, devido à própria característica do ambiente, que possui um solo arenoso e que é propício o seu assoreamento, principalmente no período de chuvas. Isso ocasiona a retirada da vegetação existente e o aparecimento das raízes e formação de erosões. Porém deve-se reforçar que a presença do turista acelera 0 agravamento desses impactos, devido ao contato direto com o solo, pois pisar nas raízes interfere na vegetação e aumenta as erosões. 
Portanto, para essa pressão, devem-se buscar estruturas que não permitam ao turista entrar em contato direto com o solo, como as passarelas suspensas que dão acesso direto ao atrativo natural.

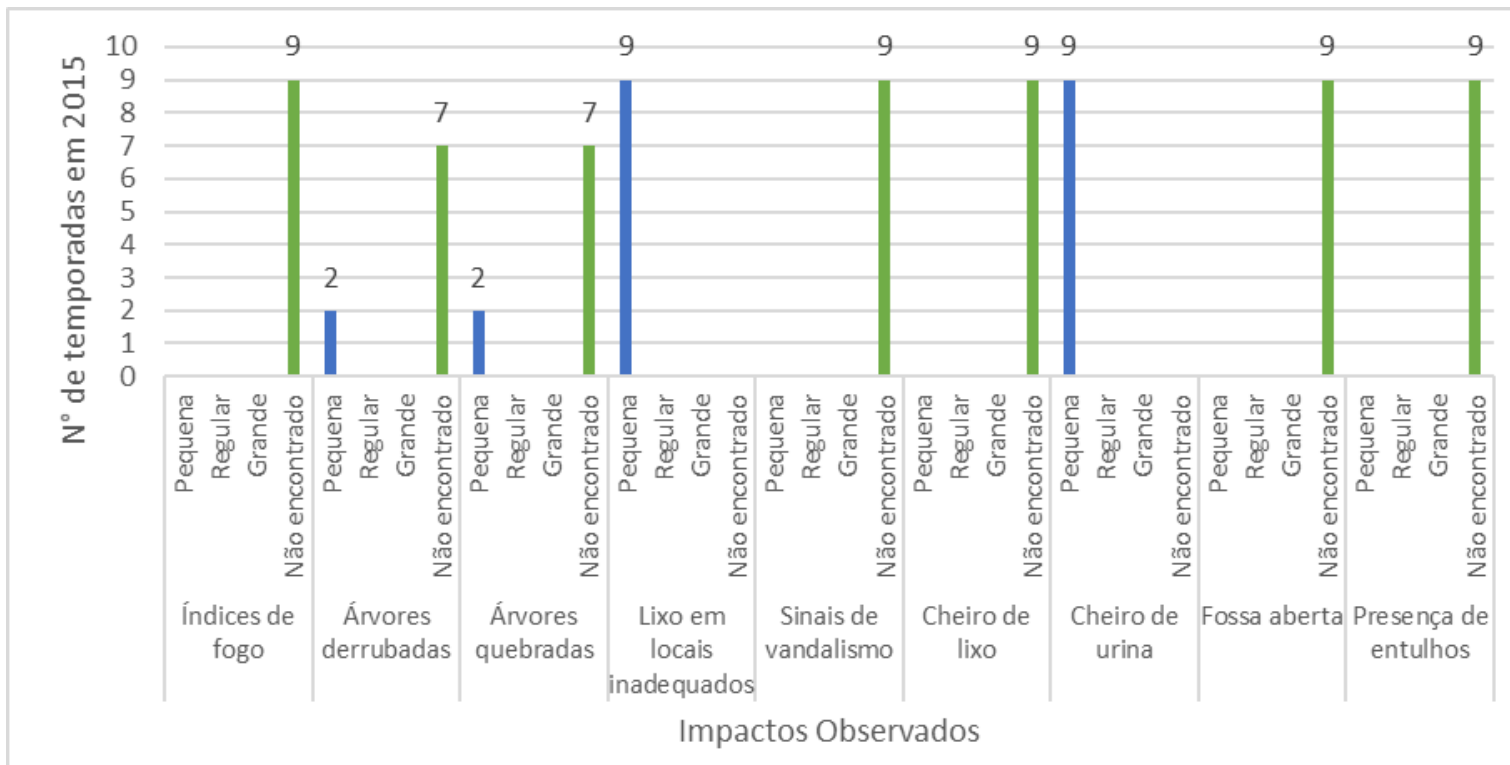

Gráfico 3: Impactos 2 Fervedouro das Bananeiras. Graph 3: Impacts 2 Fervedouro das Bananeiras.

Sobre os demais impactos monitorados (vide Gráfico 3), pode-se observar que, no caso do Fervedouro das Bananeiras, suas ocorrências mostraram-se satisfatórias, sendo que índices de fogo (que podem ser ocasionadas pelo turista ou por uma ação natural do cerrado), sinais de vandalismo, odor de lixo, fossa aberta e presença de entulhos no local não foram encontrados em nenhum dos períodos monitorados. Foram vistas, em pequena quantidade, com dois períodos de ocorrências, árvores derrubadas e árvores quebradas. Esses períodos são de chuva na região (fevereiro e novembro), o que pode ser a justificativa para o impacto ter ocorrido.

Embora a ocorrências desses impactos se mostrem como não graves, foi constatada a ocorrência de resíduos em locais inadequados e odor de urina em pequena quantidade e intensidade em todos os períodos monitorados. Ressalta-se, então, a importância de um trabalho conjunto de educação ambiental juntamente com os turistas.

No caso do odor de urina, esse impacto é justificado pela falta de banheiros para atendimento aos turistas no local. Assim, eles utilizam as matas para suas necessidades, o que ocasiona, além do odor de urina, o aparecimento de resíduos em locais muitas vezes não monitorados pelo gestor. Os impactos 1, do atrativo Cachoeira do Formiga, foram analisados no Gráfico 4. 


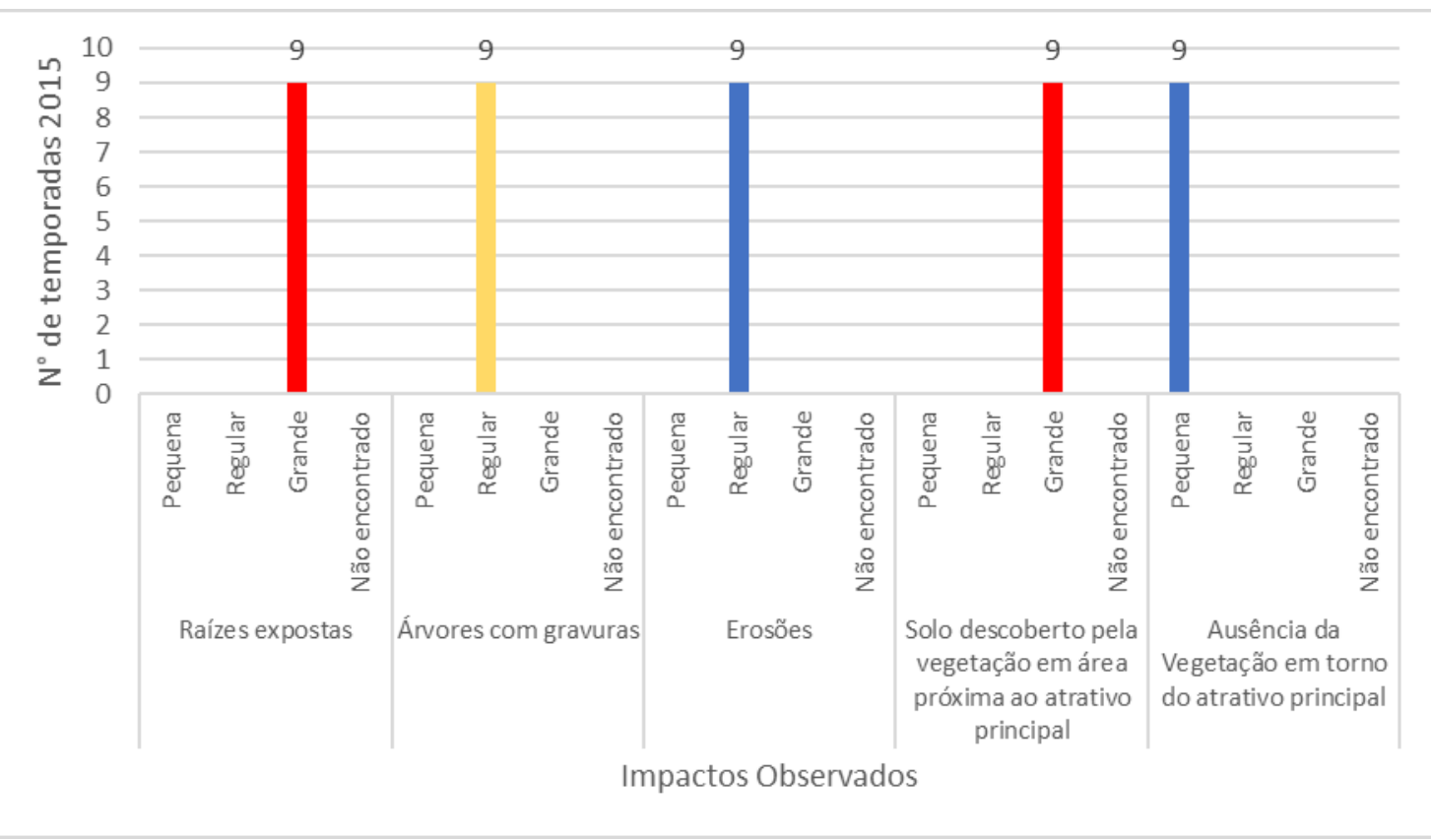

Gráfico 4 - Impactos 1 Cachoeira do Formiga.

Graph 4: Impacts 1 Ant Waterfall.

Foram encontradas em quantidade crítica as raízes expostas, o solo descoberto pela vegetação em área próxima ao atrativo principal (vide Figuras 8 e 9) e erosões e ausência de vegetação em torno do atrativo principal em pequena quantidade.
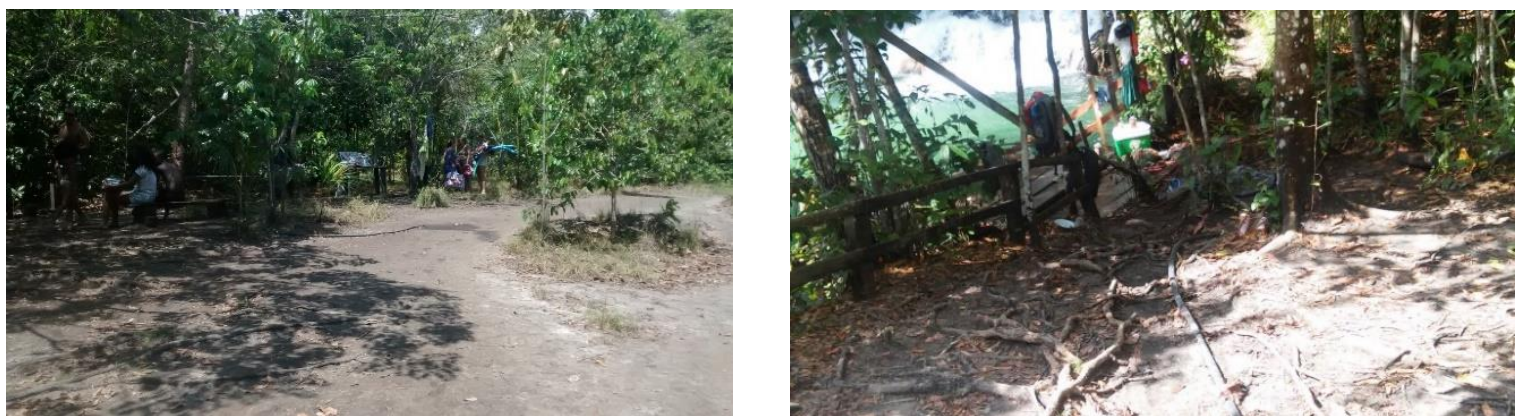

Figuras 8 e 9: Área próxima ao atrativo descoberta por vegetação e raízes expostas.

Figure 8 and 9: Area close to the attraction discovered by vegetation and exposed root.

Fotos: Dutra (2016). Photos: Dutra (2016).

Deve-se atentar para as árvores com gravuras que se mostraram com uma quantidade regular e deve-se procurar a realização de campanhas de educação ambiental no local para que não aumente essa realidade. No caso desse impacto, ele não tem como ser revertido, estando as gravuras permanentemente no ambiente até que a árvore complete seu ciclo de vida. Portanto deve-se monitorar para que outras árvores não venham a sofrer esse impacto também.

Quanto aos demais impactos, reforça-se a necessidade de implantação de estruturas apropriadas à visitação que não permitam ao turista entrar em 
contato com o solo, garantindo, assim, a sua conservação. Percebe-se que, quanto à vegetação no entorno do atrativo, foram colocadas barreiras de contenção para proibir a passagem do turista por áreas inadequadas e evitar que a vegetação seja descoberta. Porém foi visto que os turistas, com frequência ignoravam as barreiras e entravam no atrativo por esses locais, o que reforça novamente a necessidade de um programa de conscientização ambiental nos atrativos.

No que se refere aos impactos 2 no atrativo Cachoeira do Formiga (vide Gráfico 5) mostraram-se como pontos positivos o não aparecimento de ocorrências no local de índices de fogo e fossa aberta, impactos esses que podiam ser vistos constantemente no local antigamente, pela falta de banheiros e por ser área de camping. Atualmente, o local possui banheiros e estruturas determinadas para que os turistas façam churrasco. Destaca-se, também como ponto positivo, que as ocorrências de árvores quebradas também foram apenas duas e em períodos de chuva.

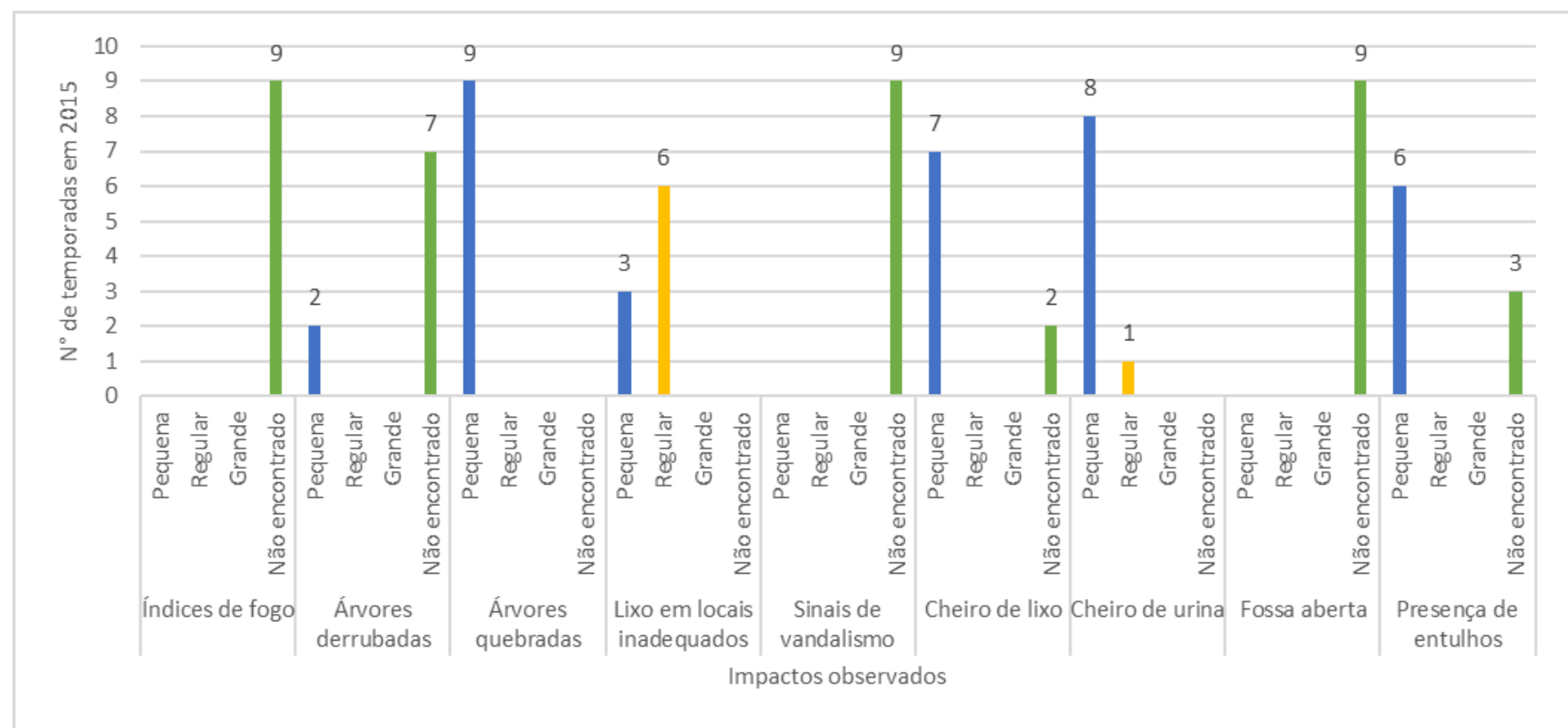

Gráfico 5: Impactos 2 Cachoeira do Formiga. Graph 5: Impacts 2 Ant Waterfall.

Embora o gestor do atrativo procure colocar placas educativas (vide Figura 10 e 11), orientando os turistas quanto à sua conduta no local, os resíduos ainda são uma preocupação, pois se pode verificar a sua ocorrência em todos os períodos monitorados. Foram encontrados seis períodos com uma quantidade de resíduos com nível regular ao final da temporada, o que, consequentemente, colabora para o surgimento do odor de lixo, que também foi verificado em todas as temporadas. Deve-se destacar que o odor de lixo também é decorrente do acúmulo de resíduos no seu local de armazenamento, que se encontra próximo à área de camping, e sua coleta pelos órgãos responsáveis não tem sido realizada constantemente. 


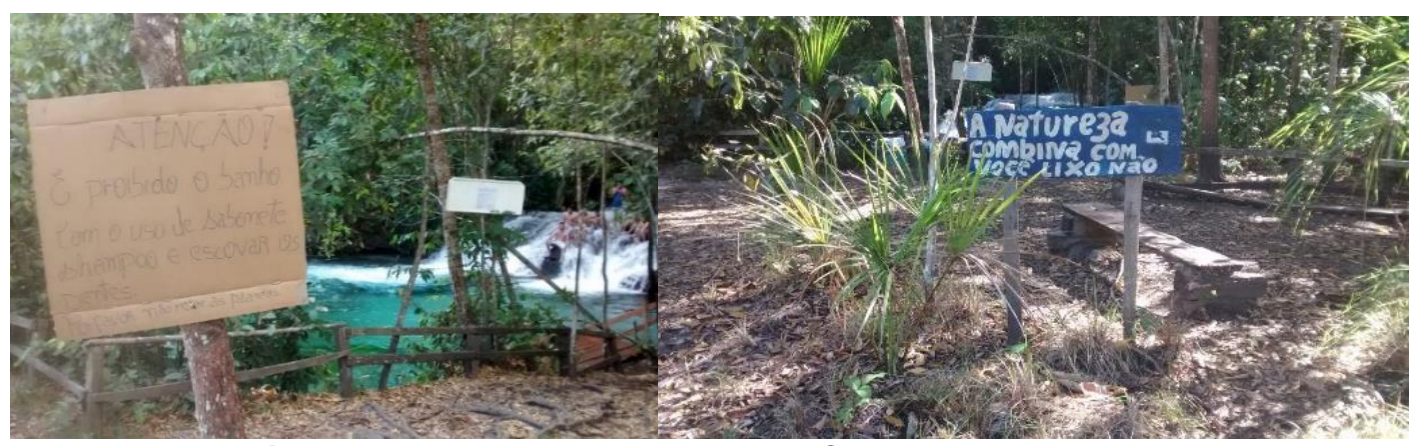

Figura 10 e 11: Placas educativa na Cachoeira da Formiga.

Figure 10 and 11: Educational plaques at Ant Waterfall.

Fotos: Dutra (2016). Photos: Dutra (2016).

Reforça-se, também, que, embora haja banheiros no atrativo, o odor de urina foi percebido em todas as temporadas.

Quanto à análise da qualidade da água para banho dos atrativos Fervedouro das Bananeiras e Cachoeira do Formiga, todas as coletas se mostraram satisfatórias durante o período monitorado (vide resultados na Tabela 1).

Tabela 1: Resultados da Análise da Qualidade de Água para Banho.

Table 1: Results of the Water Quality for Bath Analysis.

\begin{tabular}{|c|c|c|c|c|c|c|c|c|c|c|c|c|c|c|}
\hline \multirow{2}{*}{$\begin{array}{c}\begin{array}{c}\text { Pontos } \\
\text { de } \\
\text { Coleta }\end{array}\end{array}$} & \multicolumn{2}{|c|}{$\begin{array}{c}\text { Coleta } 1 \\
\text { Fevereiro }\end{array}$} & \multicolumn{2}{|c|}{$\begin{array}{c}\text { Coleta } 2 \\
\text { Maio }\end{array}$} & \multicolumn{2}{|c|}{$\begin{array}{c}\text { Coleta } 3 \\
\text { Junho }\end{array}$} & \multicolumn{2}{|c|}{$\begin{array}{c}\text { Coleta } 4 \\
\text { Julho }\end{array}$} & \multicolumn{2}{|c|}{$\begin{array}{l}\text { Coleta } 5 \\
\text { Setembro }\end{array}$} & \multicolumn{2}{|c|}{$\begin{array}{l}\text { Coleta } 6 \\
\text { Outubro }\end{array}$} & \multicolumn{2}{|c|}{$\begin{array}{c}\text { Coleta } 7 \\
\text { Novembro }\end{array}$} \\
\hline & CT & $\mathrm{CF}$ & CT & $\mathrm{CF}$ & $\mathrm{CT}$ & $\mathrm{CF}$ & $\mathrm{CT}$ & $\mathrm{CF}$ & CT & $\mathrm{CF}$ & CT & $\mathrm{CF}$ & CT & CF \\
\hline P1 & $\begin{array}{c}410.6 \\
\text { NMP } / 10 \\
0 \mathrm{ml}\end{array}$ & $\begin{array}{c}13.4 \\
\mathrm{NMP} / 10 \\
0 \mathrm{ml}\end{array}$ & $\begin{array}{c}325.5 \\
\mathrm{NMP} / 10 \\
0 \mathrm{ml}\end{array}$ & $\begin{array}{c}5.2 \\
\mathrm{NMP} / 10 \\
0 \mathrm{ml}\end{array}$ & $\begin{array}{c}307.6 \\
\mathrm{NMP} / 10 \\
0 \mathrm{ml}\end{array}$ & $\begin{array}{c}4.1 \\
\mathrm{NMP} / 10 \\
0 \mathrm{ml}\end{array}$ & $\begin{array}{c}613.1 \\
\mathrm{NMP} / 10 \\
0 \mathrm{ml}\end{array}$ & $\begin{array}{c}10.9 \\
\mathrm{NMP} / 10 \\
0 \mathrm{ml}\end{array}$ & $\begin{array}{c}0.0 \\
\mathrm{NMP} / 10 \\
0 \mathrm{ml}\end{array}$ & $\begin{array}{c}2.0 \\
\mathrm{NMP} / 10 \\
0 \mathrm{ml}\end{array}$ & $\begin{array}{c}0.0 \\
\mathrm{NMP} / 10 \\
0 \mathrm{ml}\end{array}$ & $\begin{array}{c}2.0 \\
\mathrm{NMP} / 10 \\
0 \mathrm{ml}\end{array}$ & $\begin{array}{c}0.0 \\
\mathrm{NMP} / 10 \\
0 \mathrm{ml}\end{array}$ & $\begin{array}{c}2.0 \\
\mathrm{NMP} / 10 \\
0 \mathrm{ml}\end{array}$ \\
\hline P2 & $\begin{array}{c}435.2 \\
\mathrm{NMP} / 10 \\
0 \mathrm{ml}\end{array}$ & $\begin{array}{l}13.2 \mathrm{NM} \\
\mathrm{P} / 100 \mathrm{ml}\end{array}$ & $\begin{array}{c}488.4 \\
\mathrm{NMP} / 10 \\
0 \mathrm{ml}\end{array}$ & $\begin{array}{c}3.0 \\
\mathrm{NMP} / 10 \\
0 \mathrm{ml}\end{array}$ & $\begin{array}{c}325.5 \\
\text { NMP/10 } \\
0 \mathrm{ml}\end{array}$ & $\begin{array}{c}8.6 \\
\mathrm{NMP} / 10 \\
0 \mathrm{ml}\end{array}$ & $\begin{array}{c}588.4 \\
\mathrm{NMP} / 10 \\
0 \mathrm{ml}\end{array}$ & $\begin{array}{c}37.7 \\
\mathrm{NMP} / 10 \\
0 \mathrm{ml}\end{array}$ & $\begin{array}{l}0.0 \\
\mathrm{NMP} / 10 \\
0 \mathrm{ml}\end{array}$ & $\begin{array}{c}0.0 \\
\mathrm{NMP} / 10 \\
0 \mathrm{ml}\end{array}$ & $\begin{array}{c}0.0 \\
\mathrm{NMP} / 10 \\
0 \mathrm{ml}\end{array}$ & $\begin{array}{c}0.0 \\
\mathrm{NMP} / 10 \\
0 \mathrm{ml}\end{array}$ & $\begin{array}{c}0.0 \\
\mathrm{NMP} / 10 \\
0 \mathrm{ml}\end{array}$ & $\begin{array}{c}0.0 \\
\mathrm{NMP} / 10 \\
0 \mathrm{ml}\end{array}$ \\
\hline P3 & $\begin{array}{c}613.1 \\
\text { NMP/10 } \\
0 \mathrm{ml}\end{array}$ & $\begin{array}{l}\text { 16.NMP } \\
/ 100 \mathrm{ml}\end{array}$ & $\begin{array}{c}435.2 \\
\mathrm{NMP} / 10 \\
0 \mathrm{ml}\end{array}$ & $\begin{array}{c}10.9 \\
\mathrm{NMP} / 10 \\
0 \mathrm{ml}\end{array}$ & $\begin{array}{c}387.3 \\
\mathrm{NMP} / 10 \\
0 \mathrm{ml}\end{array}$ & $\begin{array}{c}10,9 \\
\mathrm{NMP} / 10 \\
0 \mathrm{ml}\end{array}$ & $\begin{array}{c}488.4 \\
\mathrm{NMP} / 10 \\
0 \mathrm{ml}\end{array}$ & $\begin{array}{c}3.0 \\
\mathrm{NMP} / 10 \\
0 \mathrm{ml}\end{array}$ & $\begin{array}{l}0.0 \\
\mathrm{NMP} / 10 \\
0 \mathrm{ml}\end{array}$ & $\begin{array}{c}0.0 \\
\mathrm{NMP} / 10 \\
0 \mathrm{ml}\end{array}$ & $\begin{array}{c}0.0 \\
\mathrm{NMP} / 10 \\
0 \mathrm{ml}\end{array}$ & $\begin{array}{c}0.0 \\
\mathrm{NMP} / 10 \\
0 \mathrm{ml}\end{array}$ & $\begin{array}{c}0.0 \\
\mathrm{NMP} / 10 \\
0 \mathrm{ml}\end{array}$ & $\begin{array}{c}0.0 \\
\mathrm{NMP} / 10 \\
0 \mathrm{ml}\end{array}$ \\
\hline P4 & $\begin{array}{c}198.4 \\
\text { NMP/10 } \\
0 \mathrm{ml}\end{array}$ & $\begin{array}{l}25.9 \mathrm{NM} \\
\mathrm{P} / 100 \mathrm{ml}\end{array}$ & $\begin{array}{c}613.1 \\
\mathrm{NMP} / 10 \\
0 \mathrm{ml}\end{array}$ & $\begin{array}{c}96.0 \\
\mathrm{NMP} / 10 \\
0 \mathrm{ml}\end{array}$ & $\begin{array}{c}261,3 \\
\text { NMP } / 10 \\
0 \mathrm{ml}-\end{array}$ & $\begin{array}{c}6,3 \\
\mathrm{NMP} / 10 \\
0 \mathrm{ml}\end{array}$ & $\begin{array}{c}365.4 \\
\mathrm{NMP} / 10 \\
0 \mathrm{ml}\end{array}$ & $\begin{array}{c}4.1 \\
\mathrm{NMP} / 10 \\
0 \mathrm{ml}\end{array}$ & - & - & - & - & - & - \\
\hline
\end{tabular}

$\mathrm{CT}=$ Coliformes totais $\mathrm{CF}=$ Coliformes fecais $\mathrm{NMP} / 100 \mathrm{ml}=$ Número mais provável por $100 \mathrm{ml}$. $C T=$ Total coliforms; $C F=$ Fecal coliforms; NMP $/ 100 \mathrm{ml}=$ Most probable number per $100 \mathrm{ml}$.

Os resultados representados na Tabela 1, com analise final em todas as temporadas com coliformes totais e fecais $<250$ (tendo como base a Resolução Conama 274/00) (BRASIL, 1986) demonstram que os corpos aquáticos analisados nesta pesquisa apresentaram características microbiológicas excelentes para recreação de contato primário (aquele contato no qual o turista pode adentrar no poço para banho). Esse resultado é muito positivo, pois demonstra que os atrativos não sofreram, ainda, maiores impactos ambientais, portanto deve-se buscar estratégias de preservação ambiental para que permaneça nessa condição favorável.

As análises dos impactos 1 no atrativo Dunas ficam mais evidentes com no Gráfico 6. Como pode ser verificado, não foram encontradas árvores com gravuras, nem ausência da vegetação em torno do atrativo principal. 
Foram encontradas, em pequena quantidade, raízes expostas, solo descoberto pela vegetação em área próxima ao atrativo principal (no caso, nas trilhas) e erosões, o que se mostra como um ponto positivo e deve-se destacar que dos atrativos é o único que possui uma fiscalização realizada pela gestão do PEJ, o que contribui para esse resultado satisfatório. Entretanto reforça-se a necessidade de monitoramento e implantação de medidas para o não aparecimento ou aumento dos impactos verificados, com a implantação de passarelas na trilha que dá acesso ao atrativo.

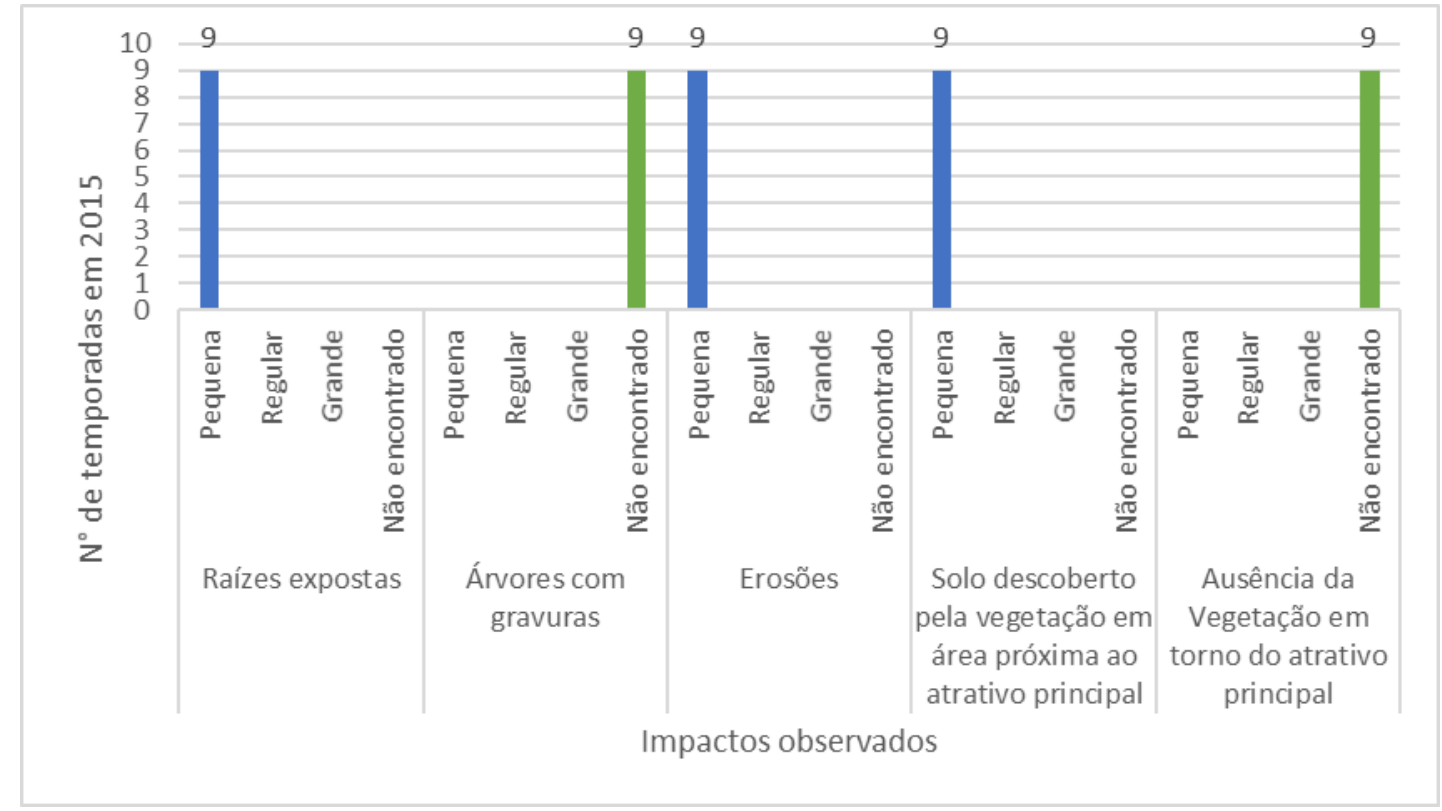

Gráfico 6: Impactos 1 Dunas.

Graph 6: Impacts 1 Dunes.

No Gráfico 7, sobre os impactos 2 observados no atrativo, também se mostra como ponto positivo o não aparecimento de ocorrências de índices de fogo. Deve-se ressaltar o trabalho da brigada de incêndio existente no PEJ que, constantemente, realiza trabalhos de orientações com os fazendeiros que se encontram próximo ao parque, contribuindo com o não aparecimento de focos de fogo no parque, como era observado constantemente há até 2 anos atrás.

Também não houve ocorrências de árvores quebradas, sinais de vandalismo, cheiro de lixo, fossas abertas, presença de entulhos no local e constatou-se, em todos os períodos, árvores derrubadas (os registros foram feitos sempre com as mesmas árvores). Segundo os gestores do parque, são impactos naturais em decorrência da incidência de fortes ventanias, no mês de agosto, que podem arrancar as árvores. 


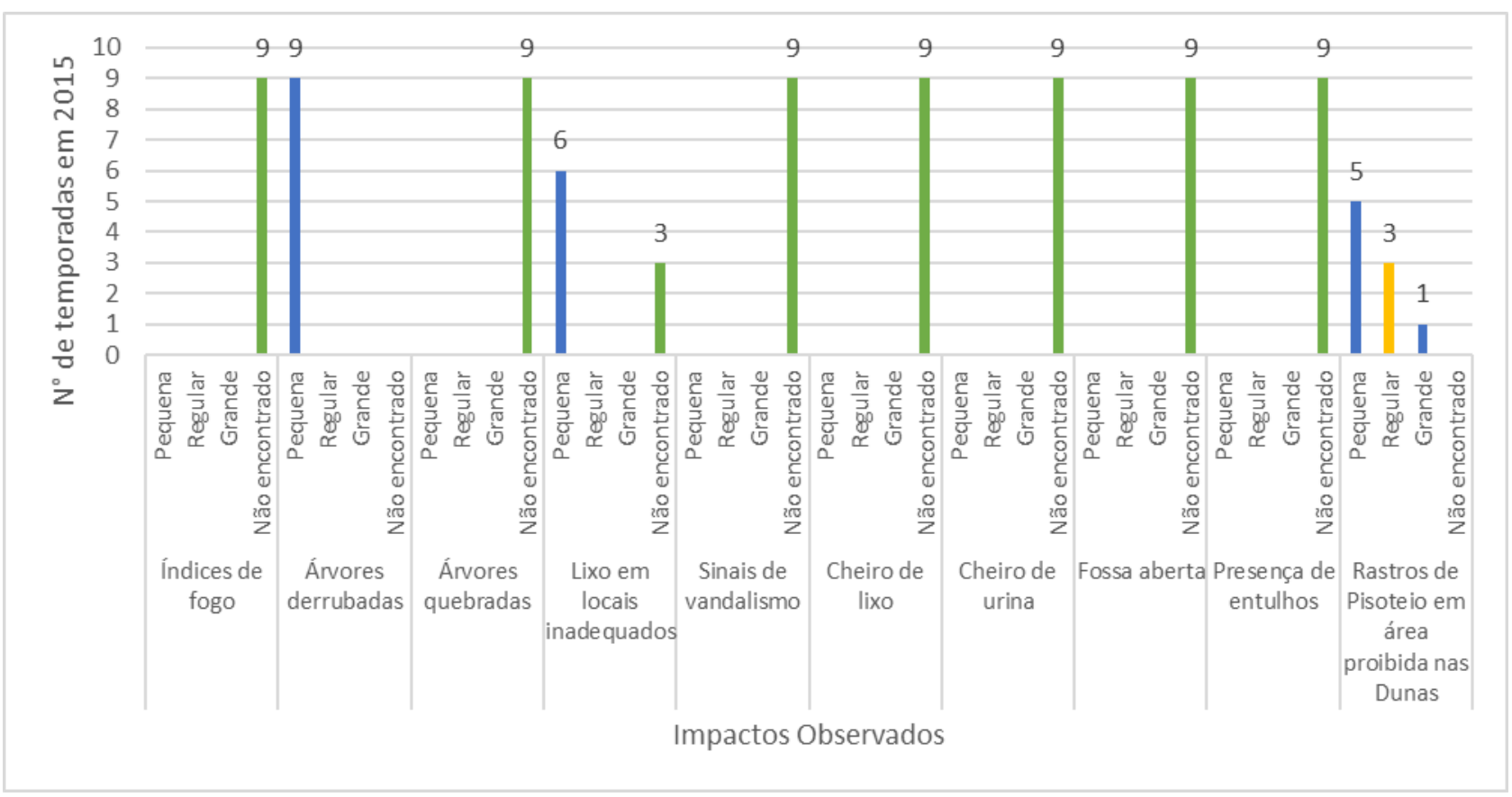

Gráfico 7: Impactos 2 Dunas.

Graph 7: Impacts 2 Dunes.

Embora o atrativo possua fiscalização, e o turista receba orientações de condutas ambientais para a visitação, antes da sua entrada no atrativo, ainda são encontrados resíduos em pequena quantidade e 0 mais preocupante são os rastros de pisoteio em áreas proibidas nas Dunas, que foram verificados em todos os períodos monitorados (vide Gráfico 7). Isso reforça a necessidade de implantação de uma sinalização ao entorno do atrativo que direcione o turista até o acesso permitido para a sua subida, bem como intensificar a sinalização com placas de educação ambiental sobre essa conduta.

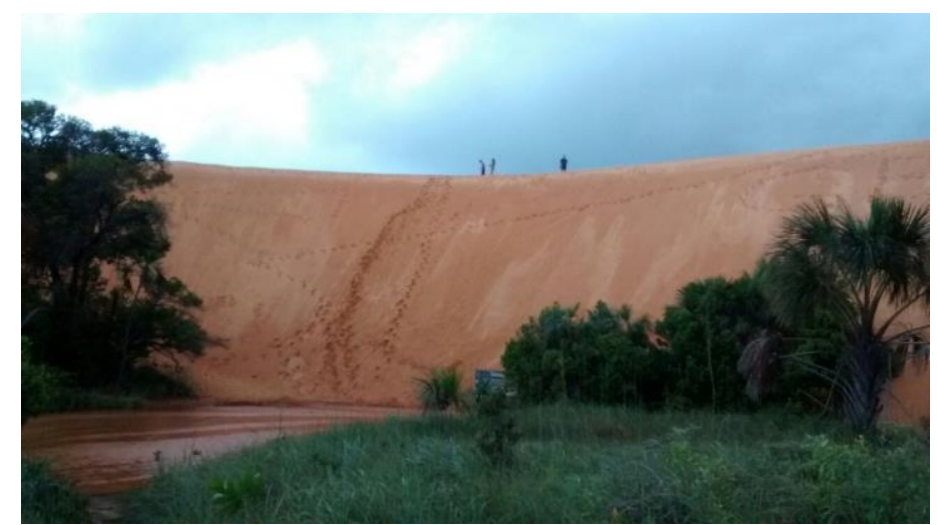

Figura 12: Rastros de pisoteio em área proibida nas Dunas/ Julho2015.

Figure 12: Traces of trampling in a forbidden area in the Dunes / July2015.

Fotos: Dutra (2016). Photos: Dutra (2016). 
Dos atrativos monitorados, a Trilha da Serra do Espírito Santo mostrouse como o que possui menos impactos (vide Gráfico 8 e 9), pois é um atrativo pouco visitado se comparado aos demais, por ser de difícil acesso e ter um perfil de público direcionado.

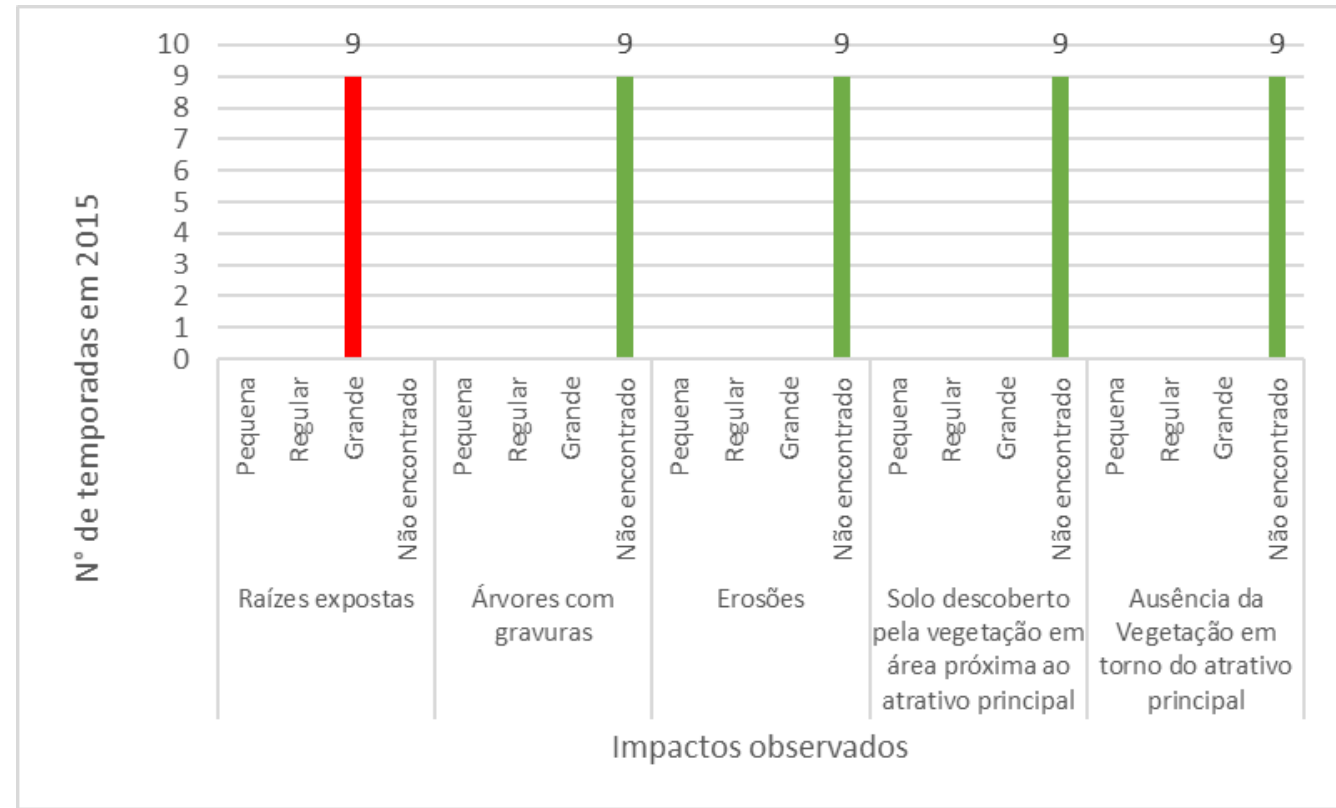

Gráfico 8: Impactos 1 Trilha da Serra do Espírito Santo.

Graph 8: Impacts 1 Serra do Espírito Santo Trail.

É possível observar, no Gráfico 8, que dos impactos fixos, foram registrados apenas raízes expostas em grande quantidade no decorrer da trilha. $O$ agravamento desse impacto pode ser reduzido com a implantação de uma estrutura adequada. A trilha possui uma estrutura que não está apropriada e, em muitos trechos, não possui uma proteção, o que ocasiona o aparecimento das raízes e riscos de acidentes aos visitantes (vide Figura 13 e 14).
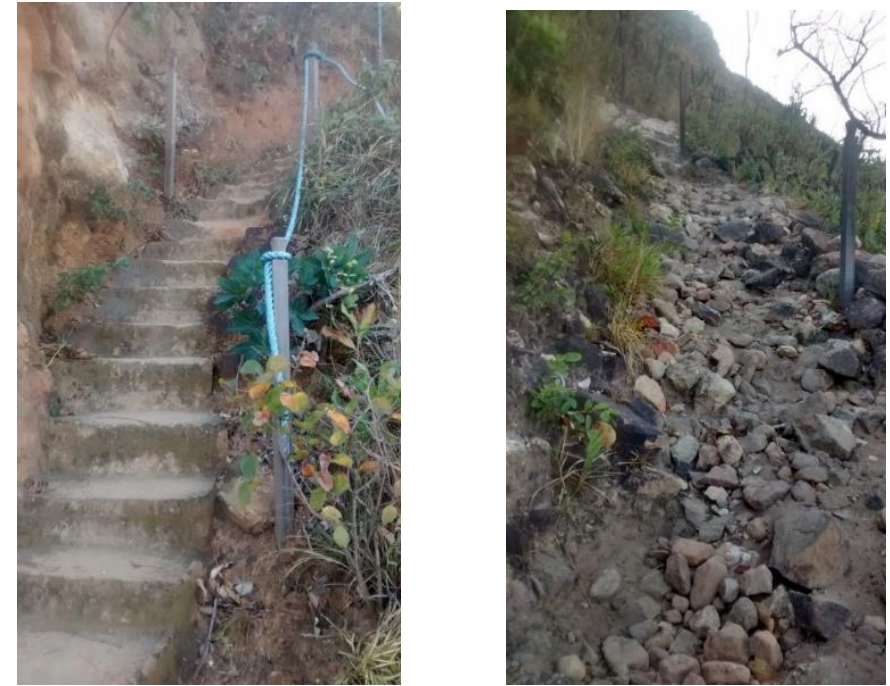

Figura 13 e 14: Trecho da trilha com estrutura. Figure 13 and 14: Track section with structure. Fotos: Dutra (2016). Photos: Dutra (2016). 
Dos impactos 2 (vide Gráfico 9), foram registradas, apenas em pequena quantidade, duas ocorrências de árvores derrubadas em períodos de chuva na região, o que pode ser uma justificativa para o impacto, pois o atrativo (que se trata de uma serra) atrai muitos raios, em período de chuva. Também pode-se observar a presença de entulhos, como restos de madeiras e cordas decorrentes do deterioramento da estrutura existente.

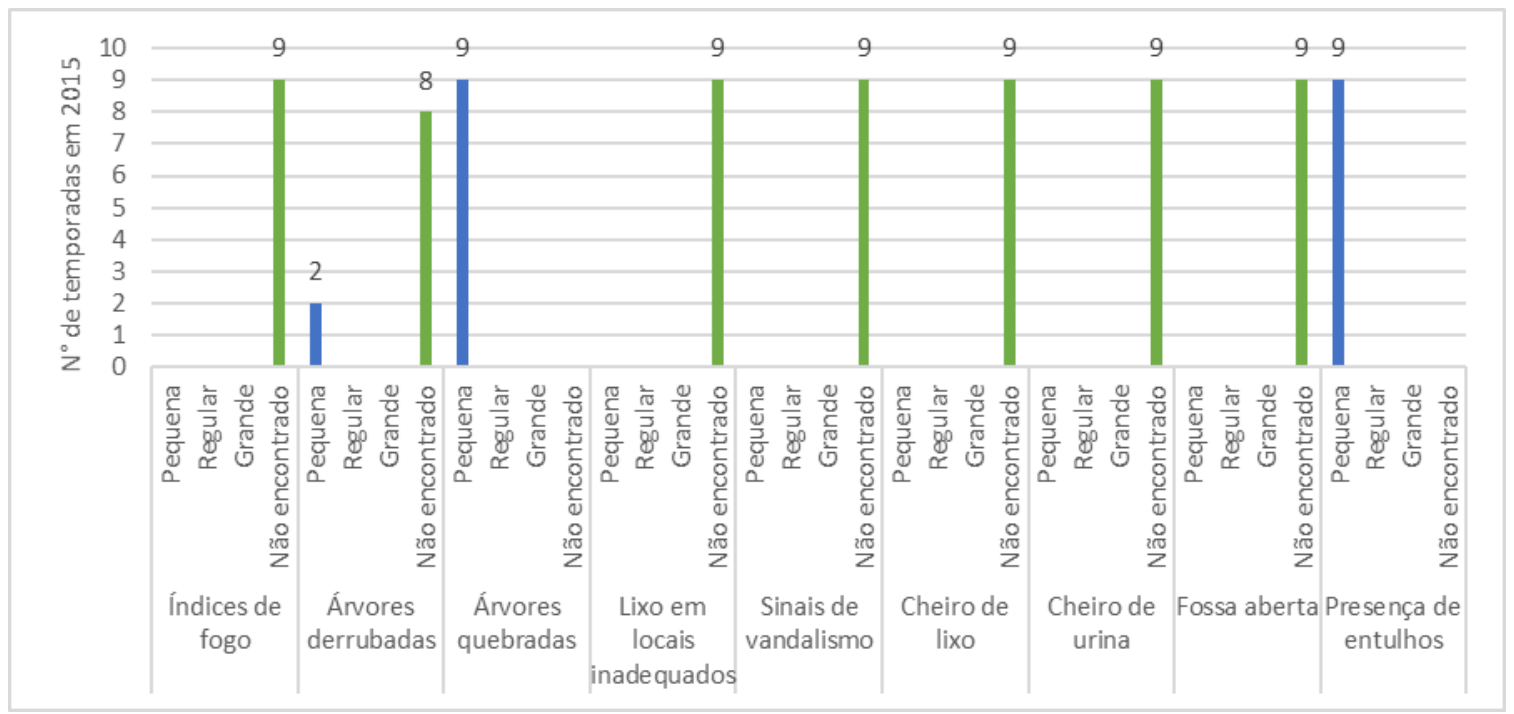

Gráfico 9: Impactos 2, trilha da Serra do Espírito Santo.

Graph 9: Impacts 1 Serra do Espírito Santo Trail.

Embora a trilha ainda receba um fluxo de visitação pequeno, se comparada aos demais atrativos, deve-se dar a ela a devida atenção, pois tem despertado o interesse dos visitantes em conhecê-la. Segundo relatos dos guias de turismo que atuam na região, o atrativo tem sido constantemente inserido no roteiro, o que não era realizado com frequência antigamente, reforçando a necessidade de busca de implantação de uma estrutura adequada e um monitoramento e controle de capacidade de carga no atrativo, para que se tenha um nível de pressão que não prejudique o ambiente.

\section{Considerações}

O indicador Pressão, que teve como proposta a mensuração do nível de pressão que os atrativos estão sofrendo com o fluxo de visitação e tendo como critérios o estabelecimento dos principais impactos que podem ocorrer nestes, mostrou-se como um indicador favorável à sua aplicação no local, uma vez que se pode quantificar a proporção que cada um desses impactos foi constatado nas temporadas de turismo e colaborar na mitigação e correção deles.

É válido destacar que a coleta das informações proposta em quantidade, embora pareça uma análise muito subjetiva, mostrou-se como a melhor opção de quantificação do impacto, pois quando se tentou a mensuração por meio da contagem do impacto (por exemplo quantas raízes 
expostas são verificadas no local), observou-se que era impossível essa contagem e a margem de erro verificada entre os pesquisadores que fizeram o cálculo era muito grande, o que consequentemente poderia levar a uma tradução não exata do indicador e quando se optou pela quantificação nas escalas pequena, regular e grande, observou-se a uniformização das respostas, o que facilitou na coleta das informações e mensuração do indicador.

No que concerne os impactos do grupo 1, apenas os mais críticos foram considerados, pois causam mudança nas características do atrativo e podem, com o tempo, não serem revertidos e devem, portanto, ter uma maior atenção, com planejamento de estratégias de recuperação da área em médio e longo prazo, assim como de prevenção, para que as mazelas não se agravarem.

Percebeu-se também, que o monitoramento da qualidade da água para banho dos atrativos turísticos se mostrou como uma proposta de controle de impacto eficaz, melhorando as condições de análise do atrativo do ponto de vista da sua utilização no turismo, proporcionando ações preventivas para o não aparecimento de impactos futuros.

Embora os resultados dos índices tenham sido satisfatórios, destaca-se que, com o aumento desordenado do número de turistas na região do Jalapão, faz-se necessário o monitoramento das atividades recreativas nos atrativos, pois diversos grupos de usuários são expostos a uma série de perigos imperceptíveis na utilização das águas dos atrativos naturais.

Quanto aos impactos do grupo 2, considerados "comuns", que surgem nos atrativos em decorrência da visitação e, todavia, não são menos importantes que os outros, pois, se não forem traçadas estratégias para o seu não aparecimento, irão interferir diretamente no ecossistema, colaborando no declínio do atrativo.

Consequentemente, devem-se buscar, para os impactos monitorados, ações de proteção ambiental para que a pressão causada pelo turismo no PEJ venha a ser adequada a fim de evitar a diminuição dos recursos naturais. A proposta de mensuração do indicador Pressão nos atrativos turísticos do local provou que esta é uma ferramenta satisfatória de monitoramento, haja vista que possibilitou a tradução dos principais impactos ambientais que ocorrem nos atrativos e sua intensidade, proporcionando, dessa forma, uma análise que visa traçar caminhos para a correção e prevenção dos problemas apresentados.

Por fim, destaca-se que o turismo é uma atividade em desenvolvimento e como outras, gera problemas complexos que demandam, em vista disso, uma continuidade de pesquisas para que se chegue a uma evolução e que se desenvolva um chamado turismo sustentável. 


\section{Referências}

APHA; AWW; WPCF. Standard Methods for the Examination of Water and Wastewater. Washington-DC, American Public Health Association, American Water Works and Water Pollution Control Federation, 20th Ed, 1992.

BEHR, M. Jalapão, sertão das águas. São José dos Campos, SP: Somos, 2004.

BRASIL. Resolução CONAMA No 20, de 18 de junho de 1986. Institui a classificação das águas, doces, salobras e salinas do Território Nacional Diário Oficial [da] República Federativa do Brasil. Brasília, DF, 30 julh.1986. Disponível em: http://www.mma.gov.br/port/conama/res/res86/res2086.html Acesso em: 22 abr.2015.

COMISSAO MUNDIAL SOBRE MEIO AMBIENTE E DESENVOLVIMENTO CMMAD. Nosso futuro comum. Rio de Janeiro, RJ: Fundação Getúlio Vargas, 1991.

CORRÊA, M.V; SOUZA, A.M. Turismo, conceitos, definições e siglas. 2.ed. Manaus, AM: Valer, 2000.

DIAS, R. Turismo sustentável e meio ambiente. São Paulo, SP: Atlas, 2003.

DUTRA, V.C. Monitoramento de Indicadores-Chave do Turismo Sustentável em Unidades de Conservação: Um Estudo de Caso no Parque Estadual do Jalapão - Tocantins.2016.296p. Tese (Doutorado em Ciências) Universidade de São Paulo, IPEN, São Paulo, 2016.

FURTADO, J.S. Indicadores de sustentabilidade e governança. Revista Intertox de Toxicologia, Risco Ambiental e Sociedade, v. 2, n. 1, p. 121188, 2009.

NÚCLEO DE ESTUDOS ESTRATÉGICOS EM AMBIENTE E TURISMO SUSTENTÁVEL - UNIVERSIDADE FEDERAL DO TOCANTINS NEATUS/UFT. Relatório Técnico Projeto Turismo no Parque Estadual do Jalapão: Identificação dos Usos e Proposição de Medidas de Controle e Monitoramento. Palmas, Patrocínio Fundação O Boticário; 2008.

ORGANIZACIÓN MUNDIAL DEL TURISMO - OMT. Indicadores de desarrollo sostenible para los destinos turísticos: guía práctica. Madrid, España: OMT, 2005.

ORGANIZAÇÃO MUNDIAL DO TURISMO - OMT. Lo que todo gestor turístico debe saber: guía práctica para el desarrollo y uso de indicadores de turismo sostenible. Madrid, España: OMT, 1997.

SEPLAN, Secretaria do Planejamento e Meio Ambiente. Plano de Manejo do Parque Estadual do Jalapão, 2003. Disponível em: www.seplan.to.gov.br Acesso em: jun. 2014.

SWARBROOKE, J. Tradução de Margarete Dias Pulido. Turismo sustentável, conceitos e impacto ambiental. São Paulo, SP: Aleph, 2000. v.1. 
Nota: O presente artigo é derivado de tese de doutorado em Ciências, pela Universidade de São Paulo, Brasil, com o título Monitoramento de Indicadores-Chave Do Turismo Sustentável em Unidades De Conservação: Um Estudo de Caso no Parque Estadual do Jalapão - Tocantins. Tendo tido como financiador o Instituto Federal de Ciências, Tecnologia e Educação do Tocantins - IFTO e apoiador o instituto Natureza do Tocantins NATURATINS, órgão gestor e fiscalizador do Parque Estadual do Jalapão.

Veruska Chemet Dutra: Instituto Federal do Tocantins, Palmas, TO, Brasil.

E-mail: veruska@ifto.edu.br

Link para o currículo Lattes: http://lattes.cnpq.br/9327094522832871

Afonso Rodrigues Aquino: Instituto de Pesquisas Energéticas e Nucleares, São Paulo, SP, Brasil.

E-mail: araquino@usp.br

Link para o currículo Lattes: http://lattes.cnpq.br/4737140717514010

Data de submissão: 07 de março de 2018

Data de recebimento de correções: 03 de julho de 2018

Data do aceite: 03 de julho de 2018

Avaliado anonimamente 